\title{
Chest Expansion and Modified Schober Measurement Values in a Healthy, Adult Population
}

\author{
Özge İLLEEZ MEMETOĞLU, ${ }^{1}$ Bülent BÜTÜN, ${ }^{2}$ İlhan SEZER ${ }^{3}$ \\ ${ }^{1}$ Department of Physical Medicine and Rehabilitation, Fatih Sultan Mehmet Training and Research Hospital, Istanbul, Turkey \\ ${ }^{2}$ Department of Physical Medicine and Rehabilitation and Rheumatology, Akdeniz University Medicine Faculty, Antalya, Turkey \\ ${ }^{3}$ Department of Rheumatology, Antalya Training and Research Hospital, Antalya, Turkey
}

\begin{abstract}
Objectives: This study aims to demonstrate chest expansion and lumbar mobility using modified Schober measurement values in healthy male and female populations aged 15 and over, and to identify factors affecting these measurements.

Patients and methods: The prospective study included 444 volunteers (195 males, 249 females; mean age 47.13 years; range 15 to 88 years) from among patients presenting to the Akdeniz University Faculty of Medicine Hospital Physical Medicine and Rehabilitation Clinic. Participants were divided into seven 10-year age groups: group 1: 15-24 years, group 2: 25-34, group 3: 35-44, group 4: 45-54, group 5: 55-64, group 6: 65-74, and group 7: over 75. Exclusion criteria comprised factors potentially influencing spinal mobility and chest expansion. All volunteers' chest measurements were performed in three planes (circumferential with a tape measure, and anteroposteriorly and transversely with calipers) and lumbar mobility was measured using the modified Schober method. The same physician performed the measurements.

Results: Chest expansion measurements using tape and calipers varied considerably in all age groups and in both sexes. While there was no difference between males and females in circumferential chest expansion measurement, there was a significant difference decrease in both sexes from group 3 and onward. The only difference between the sexes in terms of modified Schober measurement was in group 4, in favor of male sex. Age-related change in both sexes was higher at age 55 and above compared to the young age groups.

Conclusion: We may conclude that chest expansion measurement in the circumferential plane is sufficient when appropriate conditions are established and provides the most accurate result by permitting measurement in all planes.

Keywords: Chest expansion; lumbar mobility; modified Schober.
\end{abstract}

Ankylosing spondylitis (AS) is a chronic, systemic, inflammatory disease primarily involving the sacroiliac joints and spine and representing the prototype of the spondyloarthropathy group of diseases. ${ }^{1}$ The disease can vary widely, from a mild form with a restricted course involving sacroiliac joint involvement alone to being sufficiently severe to cause ankylosis of the spine. ${ }^{2}$ The key clinical symptom is inflammatory back pain. ${ }^{3}$ Pain, which increases following inactivity, awakens the individual from sleep at night and eases with exercise, results in posture impairment in the form of forward flexion due to involvement gradually progressing from the sacroiliac joints to the cervical region. ${ }^{4}$ The typical physical examination finding is loss of spinal mobility. Restriction occurs in lumbar spinal, anterior, posterior and lateral flexions and chest expansion. ${ }^{2}$ The growth of syndesmophytes along the vertebral column in these patients, fusion of the apophyseal joints and ossification of the spinal ligaments are causes of restricted spinal mobility. In addition to the involvement of the thoracic vertebrae, normal motion is compromised due to fusion of the joints at the costovertebral, costosternal, manubriosternal and sternoclavicular levels, and chest expansion is therefore significantly restricted. Restrictive respiratory diseases are 
generally diagnosed in patients, and reduced chest wall mobility is implicated rather than respiratory anomalies.5,6 Although new classification criteria7 developed by the Assessment of SpondyloArthritis International Society have frequently been used in recent years in order to identify patients with axial spondyloarthropathy in the early period, diagnosis of AS essentially relies on the modified New York criteria described in 1984. According to the 1984 modified New York criteria, chest expansion below normal values for age and sex and restriction of lower back movements in all three planes are major criteria for diagnosis of AS. ${ }^{8}$ The absence in the criteria of normal reference ranges for chest expansion and lumbar mobility in the healthy population and of guidelines involving the factors affecting these is a major deficiency. In this study, we aimed to demonstrate chest expansion and lumbar mobility using modified Schober measurement values in healthy male and female populations aged 15 and over, and to identify factors affecting these measurements. This will enable access to the required healthy population reference values for chest expansion and lumbar spinal mobility restriction, two of the major diagnostic criteria in AS.

\section{PATIENTS AND METHODS}

A total of 444 subjects (195 males and 249 females; mean age 47.13 years; range 15 to 88 years) from among patients admitted to the Akdeniz University Faculty of Medicine Hospital Physical Medicine and Rehabilitation Clinic between November 2008 to December 2009 were included. Subjects with spondyloarthropathy group diseases that restrict thoracic cage movement and reduce lumbar spinal mobility, chronic obstructive pulmonary disease, type 2 diabetes mellitus, diffuse idiopathic skeletal hyperostosis, infectious, malign or metabolic diseases of the spine or a history of spinal cord surgery or with body mass index greater than $30 \mathrm{~kg} / \mathrm{m}^{2}$ were excluded. Ethical committee approval was obtained for the study. All patients gave informed consent before the study commenced and the study was conducted in accordance with the principles of the Declaration of Helsinki. Participants' demographic characteristics including age, sex, height, weight, body mass index were investigated as well as history of any current or previous disease. Participants were divided into seven 10-year age groups: group 1: 15-24 years, group 2: 25-34, group 3: 35-44, group 4: 45-54, group 5: 55-64, group 6: 65-74, and group 7: over 75 . Group 1 consisted of 82 subjects (40 males, 42 females), group 2 of 65 (25 males, 40 females), group 3 of 62 (25 males, 37 females), group 4 of 54 (22 males, 32 females) group 5 of 53 (23 males, 30 females), group 6 of 66 (30 males, 36 females), and group 7 of 62 (30 males, 32 females). Patients were prepared for measurement unclothed from the waist up, with the arms bent, hands on heads, standing upright, and facing the front. The advantages of this posture were that

1) It prevented maximum contraction of the shoulder adductors in young males and potential exaggerated expansion resulting from this.

2) The scapula and breasts were above the measurement line, permitting free examination of the measurement area.

Circumferential measurements were performed with a tape measure, and anteroposterior and transverse measurements using caliper. Measurements were performed three times by the same physician and mean values were recorded. At circumferential measurement by tape measure; the difference between deep inspirium and deep expirium was determined by measuring chest circumferences at the level of the fourth intercostal space. For anteroposterior measurement, the front tip of the caliper was placed on the xiphisternal junction. For transverse measurement, the calipers were placed on either side of the virtual line passing through the same junction. Lumbar mobility was measured using the modified Schober technique. A $15 \mathrm{~cm}$ distance was marked $5 \mathrm{~cm}$ below to $10 \mathrm{~cm}$ above the spinous crest of the fifth lumbar vertebra at the level of the posterior superior iliac crest (dimples of Venus). ${ }^{9}$ The patient was asked to lean forward without bending the knees. Measurement was performed by determining the difference arising in this distance.

\section{Statistical analysis}

Data were analyzed on PASW version 18.0 (SPSS Inc., Chicago, IL, USA) software. Compatibility with normal distribution of constant variables was assessed using the KolmogorovSmirnov test, and homogeneity of variances with 
Table 1. Prevalence of subjects by male and female sex groups

\begin{tabular}{lcccccccc}
\hline & \multicolumn{2}{c}{ Female } & & \multicolumn{2}{c}{ Male } & & \multicolumn{2}{c}{ Total } \\
\cline { 2 - 3 } \cline { 8 - 9 } Years & $\mathrm{n}$ & $\%$ & & $\mathrm{n}$ & $\%$ & & $\mathrm{n}$ & $\%$ \\
\hline $15-24$ & 42 & 9.5 & & 40 & 9.0 & & 82 & 18.5 \\
$25-34$ & 40 & 9.0 & & 25 & 5.6 & & 65 & 14.6 \\
$35-44$ & 37 & 8.3 & & 25 & 5.6 & & 62 & 13.9 \\
$45-54$ & 32 & 7.2 & & 22 & 5.0 & & 54 & 12.2 \\
$55-64$ & 30 & 6.8 & & 23 & 5.1 & & 53 & 11.9 \\
$65-74$ & 36 & 8.1 & & 30 & 6.8 & & 66 & 14.9 \\
75 and above & 32 & 7.2 & & 30 & 6.8 & & 62 & 14.0 \\
Total & 249 & 56.1 & & 195 & 43.9 & & 444 & 100.0 \\
\hline
\end{tabular}

the Levene test. Descriptive statistics are given as median values (interval between quarters). The Bonferroni corrected Mann Whitney $U$ test was used to determine the presence of statistically significant differences in median values for clinical measurements by sex within each age group. Significance based on Bonferroni correction was set at $p<0.0071$. The Bonferroni corrected Kruskal Wallis test was used to determine the significance of differences in median values for clinical measurements between age groups among males and females. Significance based on Bonferroni correction was set at $p<0.025$. In the event that Kruskal Wallis test results were significant, the source(s) of the difference was determined using the Conover nonparametric multiple comparison test. Bonferroni correction was performed in all probable multiple comparisons in order to check for type I error.

\section{RESULTS}

Distribution of cases by age and sex groups is shown in Table 1 , and circumferential chest expansion measurements by age and sex are shown in Table 2. No significant difference was recorded between male and female sexes in any group in terms of circumferential chest expansion measurement. However, there was a significant decrease in both males and females in group 3 and onward compared to group 1.

Anteroposterior chest expansion measurements with calipers are shown in Table 3. Sex comparison revealed a statistically significant difference in favor of females in group 2 only. A statistically significant difference was determined in females between groups 1,2 , 3 and 5, 6, 7 also between group 4 and groups 5 , 7. In males, there was a statistically significant decrease between group 1 and groups 3, 6, 7 and between groups 2, 4, 5 and the group 7 .

Transverse measurement of chest expansion with calipers is shown in Table 4. Sex comparison revealed a statistically significant difference in favor of females in group 6 and group 7, in other words, only at advanced ages. No significant difference was determined among the female groups with advancing age, while statistically significant decreases in males were determined between groups 1 and groups 2, 6, 7, between group 3 and groups 6,7 , between group 4 and groups 6, 7 and between group 5 and group 7 .

Modified Schober measurements by age and sex are shown in Table 5. The only statistically significant difference between males and females was in group 4 , in favor of males. A statistically significant difference was observed in females aged 55 and over compared to the 15-44 age range. In addition, a significant decrease was observed in females aged 75 or above compared to group 4. In males, a statistically significant decrease was observed in cases aged 55 or above

Table 2. Tape measure chest expansion values by age and sex groups

\begin{tabular}{|c|c|c|c|c|c|c|c|}
\hline \multirow{2}{*}{$\begin{array}{l}\text { Age groups } \\
\text { (years) }\end{array}$} & \multicolumn{2}{|c|}{ Female } & \multirow[b]{2}{*}{$p \dagger$} & \multicolumn{2}{|c|}{ Male } & \multirow[b]{2}{*}{$p \dagger$} & \multirow[b]{2}{*}{$p \neq$} \\
\hline & Median & Min.-Max. & & Median & Min.-Max. & & \\
\hline $15-24$ & 8.0 & $7.0-9.0$ & & 8.5 & 7.5-9.4 & & 0.104 \\
\hline $25-34$ & 7.5 & $7.0-8.5$ & & 7.5 & $6.2-9.0$ & & 0.714 \\
\hline $35-44$ & 7.0 & $6.2-7.7$ & & 7.0 & $6.0-8.0$ & & 0.716 \\
\hline $45-54$ & 7.0 & $6.1-7.9$ & $<0.001$ & 7.2 & $6.4-7.5$ & $<0.001$ & 0.768 \\
\hline $55-64$ & 6.0 & $6.0-8.0$ & & 7.0 & $5.5-8.0$ & & 0.806 \\
\hline $65-74$ & 7.0 & $6.0-7.9$ & & 6.5 & $6.0-7.0$ & & 0.082 \\
\hline 75 and above & 6.5 & $6.0-7.0$ & & 5.5 & $5.0-6.5$ & & 0.008 \\
\hline
\end{tabular}


Table 3. Caliper anterior to posterior chest expansion measurements by age and sex groups

\begin{tabular}{|c|c|c|c|c|c|c|c|}
\hline \multirow{2}{*}{$\begin{array}{l}\text { Age groups } \\
\text { (years) }\end{array}$} & \multicolumn{2}{|c|}{ Female } & \multirow[b]{2}{*}{$p^{\dagger}$} & \multicolumn{2}{|c|}{ Male } & \multirow[b]{2}{*}{$p^{\dagger}$} & \multirow[b]{2}{*}{$p \neq$} \\
\hline & Median & Min.-Max. & & Median & Min.-Max. & & \\
\hline $15-24$ & 4.0 & $3.0-5.0$ & & 4.0 & $3.5-4.5$ & & 0.764 \\
\hline $25-34$ & 4.5 & $3.5-5.0$ & & 3.5 & $3.0-4.2$ & & $<0.001$ \\
\hline $35-44$ & 4.0 & $3.5-4.5$ & & 3.0 & $2.5-4.0$ & & 0.015 \\
\hline $45-54$ & 4.0 & $3.0-4.0$ & $<0.001$ & 4.0 & $3.0-4.0$ & $<0.001$ & 0.612 \\
\hline $55-64$ & 3.0 & $2.5-3.6$ & & 3.5 & $3.0-4.5$ & & 0.052 \\
\hline $65-74$ & 3.0 & $2.5-4.0$ & & 3.0 & $2.5-3.5$ & & 0.425 \\
\hline 75 and above & 3.0 & $2.0-3.5$ & & 2.7 & $2.0-3.5$ & & 0.781 \\
\hline
\end{tabular}

compared to the 25-54 age range. Additionally, a statistically significant difference was observed in subjects aged 75 and above compared to groups 1,5 , and 6 .

\section{DISCUSSION}

Ever since AS was first described by Bernard Connor, its most characteristic feature has been restricted movement of the vertebral column and thoracic cage. Restriction in chest expansion and loss of spinal mobility are amongst the modified New York diagnostic criteria ${ }^{8}$ for AS and this designates the importance of these clinical findings. These findings remain as a core domain in the evaluation of patients which was recently highlighted in the recommendations of Assessment of SpondyloArthritis International Society regarding the clinical evaluation of AS patients. ${ }^{7}$ Although determination of chest expansion is an easily applicable technique, the limited number of objective clinical studies regarding normal value ranges is surprising. ${ }^{10-14}$

Table 4. Caliper chest expansion transverse measurements by age and sex groups

\begin{tabular}{|c|c|c|c|c|c|c|c|}
\hline \multirow{2}{*}{$\begin{array}{l}\text { Age groups } \\
\text { (years) }\end{array}$} & \multicolumn{2}{|c|}{ Female } & \multirow[b]{2}{*}{$p \dagger$} & \multicolumn{2}{|c|}{ Male } & \multirow[b]{2}{*}{$p \dagger$} & \multirow[b]{2}{*}{$p \neq$} \\
\hline & Median & Min.-Max. & & Median & Min.-Max. & & \\
\hline $15-24$ & 4.0 & $3.5-5.0$ & & 5.0 & $3.6-5.4$ & & 0.066 \\
\hline $25-34$ & 5.0 & $3.6-5.0$ & & 3.5 & $3.0-4.7$ & & 0.013 \\
\hline $35-44$ & 4.5 & 3.5-5.0 & & 4.0 & $3.7-5.0$ & & 0.684 \\
\hline $45-54$ & 4.5 & $4.0-5.0$ & 0.092 & 4.5 & 3.9-5.0 & $<0.001$ & 0.372 \\
\hline $55-64$ & 5.0 & $3.9-5.6$ & & 4.0 & $3.0-4.5$ & & 0.020 \\
\hline $65-74$ & 4.0 & $4.0-5.0$ & & 3.5 & $3.0-4.0$ & & $<0.001$ \\
\hline 75 and above & 4.0 & $3.0-4.9$ & & 3.0 & $2.4-4.0$ & & 0.006 \\
\hline
\end{tabular}

Table 5. Modified Schober measurements by age and sex groups

\begin{tabular}{|c|c|c|c|c|c|c|c|}
\hline \multirow{2}{*}{$\begin{array}{l}\text { Age groups } \\
\text { (years) }\end{array}$} & \multicolumn{2}{|c|}{ Female } & \multirow[b]{2}{*}{$p \dagger$} & \multicolumn{2}{|c|}{ Male } & \multirow[b]{2}{*}{$p \dagger$} & \multirow[b]{2}{*}{$p \neq$} \\
\hline & Median & Min.-Max. & & Median & Min.-Max. & & \\
\hline $15-24$ & 6.9 & $6.2-7.3$ & & 6.8 & $6.2-7.8$ & & 0.531 \\
\hline $25-34$ & 6.8 & $6.2-7.5$ & & 7.3 & $6.7-8.0$ & & 0.089 \\
\hline $35-44$ & 7.0 & $6.2-7.4$ & & 7.5 & $6.6-8.1$ & & 0.046 \\
\hline $45-54$ & 6.2 & $5.5-7.0$ & $<0.001$ & 6.8 & $6.5-7.8$ & $<0.001$ & 0.002 \\
\hline $55-64$ & 6.0 & $5.5-7.0$ & & 6.5 & $6.0-7.5$ & & 0.063 \\
\hline $65-74$ & 5.9 & $5.2-6.6$ & & 6.5 & $5.9-6.9$ & & 0.033 \\
\hline 75 and above & 5.2 & $5.0-6.1$ & & 5.5 & $5.1-6.3$ & & 0.216 \\
\hline
\end{tabular}


These studies have been performed in populations involving specific sex or ages, and it is impossible to compare them directly.

First comprehensive study on the subject was performed by Moll and Wright ${ }^{10}$ in 1972. Chest expansion was measured in 262 healthy individuals (111 males and 151 females). Thoracic cage measurements were performed in three planes, using tape measure and calipers, which also served as the model for our study. The fourth intercostal space was used in circumferential measurement by tape measure and the xiphisternal junction in anterior to posterior measurement using calipers. As in our study, mean chest expansion values decreased gradually but significantly with age, apart from a slight initial increase. In contrast to our results, expansion was $13 \%$ to $22 \%$ higher in males than in females. The most important conclusion from the study is that normal values exhibit a wide range distribution in all age groups. In their study, Moll and Wright ${ }^{10}$ recommended that the $2.5 \mathrm{~cm}$ rigid value accepted at the New York Symposium should be abandoned. That value was duly removed from the modified New York criteria adopted in 1984. That same declaration referred to normal values by age and sex for chest expansion but proposed no subjective measurement interval.

Another noteworthy point is that chest expansion may decrease in various diseases other than spondylitis. Therefore, decreased chest expansion is not a finding specific to spondylitis, and care is needed over potential false positives due to similar underlying conditions. Patients with spondyloarthropathy, chronic lung disease, obesity, diffuse idiopathic skeletal hyperostosis and diabetes mellitus and hypoparathyroidism that may give rise to diffuse idiopathic skeletal hyperostosis-like pictures were excluded from our study.

We observed a statistically significant decrease in circumferential chest expansion measurements from group 3 and onward. We attributed this to ageing-related structural changes in the chest wall and thoracic spine leading to decreased chest expansion and to mild aging-related increases in airway resistance and pulmonary dimensions. ${ }^{15}$ This is compatible with Moll and Wright's study. ${ }^{10}$ However, although chest expansion was higher in males than in females in studies of Moll and
Wright ${ }^{10}$ and Adedoyin et al., ${ }^{11}$ there was no difference between males and females at any age in our study. Since higher chest expansion values are to be expected in young, healthy, nonsmoking and exercising individuals, we think that this finding can be attributed to females working actively at home and work and participating in at least as much sporting activity as males.

Modified Schober values decrease after the age of 55 in both males and females. Similarly, this decrease in spinal mobility was present above the age of 40 in the study of Finnsback and Mannerkorpi ${ }^{12}$ and above 50 in the study of Intolo et al. ${ }^{16}$ We think that lumbar spinal mobility may decrease in association with changes such as levels of activity declining with age, increased degenerative changes, atrophy and weakness in the muscles and weakening in the ligaments. While not a one-to-one comparison, Mellin ${ }^{17}$ investigated the relationship between age and anthropometric factors and spinal mobility. Four hundred seventy-six individuals were assessed, and a significant age-related decrease in mobility was determined. Another study investigating the effects on lumbar segmental mobility of degeneration, ageing and other factors, reported an age-related decrease in mobility in the first four lumbar segments in particular. ${ }^{18}$

In contrast to our study, one study published in 2012 involving 428 participants aged 20 to 70 measured chest expansion in two different forms, as upper and lower thoracic. ${ }^{11}$ Chest expansion increased until the third decade and then decreased. Chest expansion in males was significantly greater than that in females. ${ }^{11}$ Furthermore, in another study published in Turkey in 2012, chest expansion was measured in 1982 healthy Turkish males aged 20 to 30 using Schober and modified Schober methods. ${ }^{13}$ Lower value ranges were determined compared to the results of similar studies involving young, healthy male populations from other countries. The authors suggested that racial differences should be considered in interpreting the results. ${ }^{13}$

Moll and Wright ${ }^{10}$ maintained that since chest expansion measurements in all three planes produce similar results, expansion measurement in a single plane is sufficient for clinical and epidemiological purposes. That same study reported that circumferential measurement can be 
used as a routine form of measurement. Expansion measurement with calipers is not a routine technique. Regarding expansion measurement with calipers; in addition to the lack of any standardization in devices used, the fact that its validity and reliability have not been confirmed, and the possibility of different results in the same plane in the same individual depending on the person doing the measuring may all lead to false results in measurements performed using calipers. We think that chest expansion measurement in the circumferential plane is sufficient when appropriate conditions are established (from the fourth intercostal space, in a suitable posture, without applying the measure too tightly) and provides the most accurate result by permitting measurement in all planes.

In conclusion, even if significant progress has been made in early diagnosis with the new classification criteria developed by the Assessment of SpondyloArthritis International Society, knowledge of normal value ranges obtained in this and similar studies, as well as range intervals appropriate to the patient's age and sex might be useful at both initial examination and subsequent monitoring. Normal value studies representing larger communities are therefore needed.

\section{Declaration of conflicting interests}

The authors declared no conflicts of interest with respect to the authorship and/or publication of this article.

\section{Funding}

The authors received no financial support for the research and/or authorship of this article.

\section{REFERENCES}

1. Sengupta R, Stone MA. The assessment of ankylosing spondylitis in clinical practice. Nat Clin Pract Rheumatol 2007;3:496-503.

2. Khan MA. Clinical features of ankylosing spondylitis. In: Hochberg MC, Silman AJ, Smolen JS, Weinblatt ME, Weisman MH, editors. Rheumatology. 3rd ed. Vol. 2. Edinburg: Mosby, Elsevier Limited; 2003. p. 1161-81.

3. Sieper J, Braun J, Rudwaleit M, Boonen A, Zink A.
Ankylosing spondylitis: an overview. Ann Rheum Dis 2002;61 Suppl 3:iii8-18.

4. Akar S, Birlik M, Aksu K, Senocak O, Akkoc N, Kabasakal Y, et al. Clinical history for inflammatory back pain in ankylosing spondylitis: the sensitivity, specificity and consistency of clinical features. Rheumatol Int 2009;29:349-51.

5. Tam LS, Gu J, Yu D. Pathogenesis of ankylosing spondylitis. Nat Rev Rheumatol 2010;6:399-405.

6. Quismorio FP Jr. Pulmonary involvement in ankylosing spondylitis. Curr Opin Pulm Med 2006;12:342-5.

7. Sieper J, Rudwaleit M, Baraliakos X, Brandt J, Braun J, Burgos-Vargas R, et al. The Assessment of Spondylo Arthritis international Society (ASAS) handbook: a guide to assess spondyloarthritis. Ann Rheum Dis 2009;68 Suppl 2:ii1-44.

8. van der Linden S, Valkenburg HA, Cats A. Evaluation of diagnostic criteria for ankylosing spondylitis. A proposal for modification of the New York criteria. Arthritis Rheum 1984;27:361-8.

9. Viitanen JV, Heikkilä S, Kokko ML, Kautiainen H. Clinical assessment of spinal mobility measurements in ankylosing spondylitis: a compact set for follow-up and trials? Clin Rheumatol 2000;19:131-7.

10. Moll JM, Wright $V$. An objective clinical study of chest expansion. Ann Rheum Dis 1972;31:1-8.

11. Adedoyin RA, Adeleke OE, Fehintola AO, Erhabor GE, Bisiriyu LA. Reference values for chest expansion among adult residents in ile-ife. $\mathrm{J}$ Yoga Phys Ther 2012;2:113.

12. Finnsback C, Mannerkorpi K. Spinal and thoracic mobility age-related reference values for healthy men and women. Nordisk Fysioterapi 2005;9:136-43.

13. Cidem M, Karacan I, Uludag M. Normal range of spinal mobility for healthy young adult Turkish men. Rheumatol Int 2012;32:2265-9.

14. Chilton-Mitchell L, Martindale J, Hart A, Goodacre L. Normative values for the Bath Ankylosing Spondylitis Metrology Index in a UK population. Rheumatology (Oxford) 2013;52:2086-90.

15. Knudson RJ. How aging affects the normal lung. J Respir Dis 1981;2:74-84.

16. Intolo P, Milosavljevic S, Baxter DG, Carman AB, Pal P, Munn J. The effect of age on lumbar range of motion: a systematic review. Man Ther 2009;14:596-604.

17. Mellin G. Correlations of spinal mobility with degree of chronic low back pain after correction for age and anthropometric factors. Spine (Phila Pa 1976) 1987; 12:464-8.

18. Bible JE, Simpson AK, Emerson JW, Biswas D, Grauer JN. Quantifying the effects of degeneration and other patient factors on lumbar segmental range of motion using multivariate analysis. Spine (Phila $\mathrm{Pa}$ 1976) $2008 ; 33: 1793-9$. 